Article (refereed) - postprint

Roy, D.B.; Ploquin, E.F.; Randle, Z.; Risely, K.; Botham, M.S.; Middlebrook, I.; Noble, D.; Cruickshanks, K.; Freeman, S.N.; Brereton, T.M. 2015.

Comparison of trends in butterfly populations between monitoring schemes. Journal of Insect Conservation, 19 (2). 313-324. 10.1007/s10841-014-9739-0

(C) Springer International Publishing Switzerland 2014

This version available http://nora.nerc.ac.uk/509971/

NERC has developed NORA to enable users to access research outputs wholly or partially funded by NERC. Copyright and other rights for material on this site are retained by the rights owners. Users should read the terms and conditions of use of this material at

http://nora.nerc.ac.uk/policies.html\#access

This document is the author's final manuscript version of the journal article, incorporating any revisions agreed during the peer review process. Some differences between this and the publisher's version remain. You are advised to consult the publisher's version if you wish to cite from this article.

The final publication is available at Springer via http://dx.doi.org/10.1007/s10841-014-9739-0

Contact CEH NORA team at noraceh@ceh.ac.uk

The NERC and CEH trademarks and logos ('the Trademarks') are registered trademarks of NERC in the UK and other countries, and may not be used without the prior written consent of the Trademark owner. 


\section{Comparison of trends in butterfly populations between monitoring schemes}

2 Roy, D.B. ${ }^{1}$, Ploquin, E.F. ${ }^{1}$, Randle, Z. ${ }^{2}$, Risely, K. ${ }^{3}$, Botham, M.S. ${ }^{1}$, Middlebrook, I. ${ }^{2}$, Noble, D. ${ }^{3}$,

3 Cruickshanks, K. ${ }^{4}$, Freeman, S.N. ${ }^{1}$ \& Brereton, T.M. ${ }^{2}$

4

$5 \quad{ }^{1}$ NERC Centre for Ecology \& Hydrology, UK

$6 \quad{ }^{2}$ Butterfly Conservation, Wareham, UK

$7 \quad{ }^{3}$ British Trust for Ornithology, Thetford, UK

$8 \quad{ }^{4}$ Footprint Ecology, Wareham, UK

9

10 Corresponding author: D.B. Roy. NERC Centre for Ecology \& Hydrology, Wallingford, UK

11 Email: dbr@ceh.ac.uk

12

13

14

15 Keywords: Butterfly Monitoring Scheme; Lepidoptera; citizen science; abundance trends;

16 biodiversity indicators 


\section{Abstract}

18 Butterflies are an important indicator of the impacts of environmental change. Butterfly Monitoring 19 Schemes have provided national and Europe-wide trends in their abundance and been widely used 20 for research. Most schemes sample sites that are self-selected by contributors and therefore tend 21 to cover locations that are rich in butterflies. To provide a more representative assessment of 22 butterfly populations, the Wider Countryside Butterfly Survey (WCBS) was developed with a 23 stratified-random sample of survey sites across the UK. We compare butterfly trends from the 24 WCBS locations against those measured from traditional butterfly transects which are typically 25 located in areas of good quality semi-natural habitats. Across the 26 species analysed, there was a significant positive relationship between trends measured from the two schemes between 2009 and 2013 , the period when both schemes were operating fully. There was a tendency (17 out of 26 species analysed) for these changes to be greater within WCBS compared to traditional BMS transects, although this effect was not consistent across comparisons between pairs of consecutive years. When assessing these individual year-to-year changes, there was however a significant correlation between the two schemes in all cases. Over relatively short time periods, weather patterns are likely to dominate butterfly population fluctuations and lead to comparable trends across monitoring schemes. Over longer time periods, differences in land management may affect habitat condition differently for protected areas versus the wider countryside and it is therefore important to maintain comprehensive butterfly monitoring programmes to detect and interpret such effects. 


\section{Introduction}

Parties to the United Nations (UN) Convention on Biological Diversity (CBD) recognise the need to reduce the rate of biodiversity loss (CBD 2010). Monitoring of species' populations is one of the key biodiversity variables for measuring progress against national goals and targets for conserving biodiversity (Pereira et al. 2013), as well as providing the additional benefits of being a rich resource for fundamental research (Fisher et al. 2010), policy and conservation management (Pereira et al. 2012).

Monitoring by standardised counts has been successful for a limited set of taxa but remains severely geographically restricted, with most programmes operating in developed countries (Pereira et al. 2010). Insect populations pose particular problems for monitoring as they are species-rich (representing an estimated 50-60\% of all known species on earth) and require specialist skills for many families (Brereton et al. 2011a; Thomas 2005). The role of insect monitoring for measuring biodiversity change is recognised by the growing body of literature about the processes driving change in insect populations (Dempster and McLean 1998) and evidence that well-studied groups of insects are representative of obscure ones (Thomas and Clarke 2004). Insects play a key role in many ecosystem functions and key links in food webs, including as a major food resource for insectivorous animals (Strong et al. 1984).

Butterflies are the insect group for which monitoring of trends has proved most tractable, at least in some parts of the world. Butterflies have been advocated as indicator taxa due to their rapid and sensitive responses to habitat and climate change, and their potential to represent change in other wildlife, especially insects (e.g. Thomas 2005). Several butterfly species which reach their northern range margin in Britain have expanded their range in the past four decades, in common with other insects (Chen et al. 2011; Hickling et al. 2006), linked to improved climatic conditions (Warren et al. 2001). However, butterfly species with more specialised habitat requirements have decline over a similar period through the loss of habitat. As a group, butterflies are contracting more 
rapidly than either birds or plants in Great Britain (Thomas et al. 2004), emphasising their potential importance for assessing the status of biodiversity beyond more charismatic groups.

Schemes to measure relative change in the abundance of butterflies were established in the 1970s (Pollard 1977) and have expanded to more than 20 countries around the world, although predominantly within Europe and North America. Sampling is predominantly undertaken by volunteer contributors, continuing the rich tradition of citizen involvement (especially by amateur experts) in monitoring (Miller-Rushing and Primack 2008). Citizen science, including participatory schemes for monitoring butterflies, is increasingly being recognised as the only practical way of gathering the biodiversity data required to identify and address large-scale, long-term changes in biodiversity (Hochachka et al. 2012).

One of the disadvantages of volunteer-based monitoring schemes, and citizen science more generally, is potential bias, particularly if contributors are given a free choice in where to survey, leading to geographic bias in results (Gregory et al. 2005). For most butterfly monitoring schemes, volunteer recorders undertake sampling at locations they select which leads to a tendency to monitor areas rich in butterflies. Such a bias has provided good coverage of sites with environmental protection and semi-natural habitats that support butterfly diversity, but may not provide representative trends in species that are common elsewhere. In the heavily-modified landscape of the United Kingdom, evidence suggests that declines in many butterflies away from sites protected for nature conservation were largely undetected by monitoring and mapping schemes (Cowley et al. 1999).

Intensively farmed areas dominate the UK landscape yet are typically under-represented by butterfly monitoring schemes, mainly because they support a relatively depauperate butterfly fauna. Voluntary recorders are often reluctant to sample in areas where they see only a few individuals of a few common species, particularly when a high level of within-season repeat sampling is required; long-established butterfly monitoring schemes advocate weekly sampling throughout the main season of butterfly activity ( 26 weeks in the United Kingdom). Increasingly, the need for surveys to 
cover all regions and habitats appropriately is being recognised by conservationists; for example the (intensive, self-selected) Common Birds Census was replaced by the less intensive, but more representative, BTO/JNCC/RSPB Breeding Bird Survey (BBS) based on randomly selected sites (Freeman et al 2007). To address the limitations of traditional butterfly monitoring schemes, a stratified-random sampling schemes with less within-year sampling has therefore been designed (Roy et al. 2007) and implemented within the United Kingdom as the Wider Countryside Butterfly Survey, WCBS (Brereton et al. 2011b). The design of the survey closely matches that of the BBS, and indeed many of the sites are common to both.

This paper compares year-to-year growth rates in butterfly populations between 2007 and 2013 from the WCBS and traditional transects, hereafter termed traditional Butterfly Monitoring Scheme transects (also referred to as Pollard Walks). The WCBS was launched in 2009 following two pilot years and we compare year-to-year and overall population growth rates (2007-2013) for the scheme with those of the traditional BMS at the same time of the year. This comparison is undertaken to assess whether differences are apparent in butterfly trends between the two networks of sites, and to provide a basis for producing representative assessments of butterfly population trends in the UK by combining data from both surveys (Dennis et al. 2013).

\section{Methods}

\section{Traditional Butterfly Monitoring Scheme (tBMS)}

The first national scheme to monitor butterflies was initiated in the United Kingdom in 1976. The scheme is based on a standardized method, described in detail elsewhere (Pollard \& Yates 1993). A fixed transect route is walked at least once a week from 1 April to 29 September, under defined weather conditions and at specified times of the day when adult butterflies are active. Every sighting of each species made in an imaginary, fixed 5-m box around the recorder is counted. Transect routes are $1.9 \mathrm{~km}$ long on average (median) and therefore cover multiple $1 \mathrm{~km}$ grid squares; we use the central $1 \mathrm{~km}$ grid reference to characterise the coverage of the network. Traditional BMS 
transect routes are established by recorders, with only general guidance provided by the scheme coordinators. In this paper, we label the traditional BMS transects using the acronym tBMS.

Wider Countryside Butterfly Monitoring Scheme (WCBS)

The key difference between the Wider Countryside Butterfly Survey (WCBS) and traditional

BMS is that volunteer surveyors are allocated a randomly selected $1 \mathrm{~km}^{2}$ square within their local region (Brereton et al. 2011b). WCBS locations are selected at random, with a larger number of $1 \mathrm{~km}$ grid squares surveyed in regions with a higher density of recorders (the strata for selection). A total of 755 grid squares were surveyed in 2009 (Figure 1), the launch year for the scheme; the scheme had two pilot years in 2007 and 2008, with reduced sampling. Within each grid square, two parallel, $1 \mathrm{~km}$ long, fixed transects were established. Volunteers walked these transects twice within July and August (additional visits are also permitted outside these months) with most other aspects of the survey the same as for traditional transect, i.e. weather and time of day criteria and line sampling criteria (Brereton et al. 2011b). A further difference of the WCBS is the strip-width of the linear transect is $10 \mathrm{~m}$ ( $5 \mathrm{~m}$ each side of the recorder) as opposed to $5 \mathrm{~m}$ ( $2.5 \mathrm{~m}$ each side of the recorder) for the tradition BMS.

\section{Data selection}

Other than selection of sites and line transect length, the two surveys of the UKBMS are equivalent and therefore the data arising are similar in form. Analysis of seasonal insect population abundance requires account to be taken of pronounced variation in numbers across the season, commonly via the estimation of a seasonal correction factor (Dennis et al. 2013; Matechou et al. 2014; Rothery and Roy 2001). For this reason, and as the WCBS is nominally restricted to two visits in

137 the months of July and August (though there are limited additional data from beyond this period), data in this analysis are restricted to these months only. The WCBS dataset therefore comprises 1 or 2 visits per year whereas the traditional BMS dataset comprises between 1 and 8 weekly visits. We 
restrict analysis to the years covered so far by the scheme (2007-2012, including 'pilot' years for which a reasonable amount of data are available). Due to differences in protocol (weekly visits for the traditional BMS, compared to monthly for the WCBS), more data is available for the traditional BMS although the number of sites within each species is similar ( $750-1000$ sites sampled each year for both schemes). We restrict analysis to species occurring in more than 25 sites in each network. tBMS) $1 \mathrm{~km}$ sites to seven Environmental Zones defined for the UK (Carey et al. 2008). In order to characterise the habitat coverage of the two schemes, we summarise the land cover of all $1 \mathrm{~km}$ grid cells covered by the UKBMS surveys (WCBS and tBMS) using the Centre for Ecology \& Hydrology Land Cover Map (Morton et al. 2011).

\section{Statistical model} counts of a species made in a total of $v_{i, t}$ visits in year $t$ to site $i$ are defined as $\mu_{\mathrm{i}, \mathrm{t}}$. We further assume that annual proportional changes in abundance over consecutive years are identical at all counts, per visit made, in years $t$ and $t+1$ can be written as follows: model is impractical to fit; the ratios of consecutive counts observed are undefined wherever the count in year $t$ is zero or (as is often the case) the site was not visited during that year. Merely to 
data. However, if we further define $\mu_{i, t}^{\prime}=\mu_{i, t} / v_{i, t}$ then $\log \left(\mu_{i, 1}\right)=\log \left(\mu_{i, 1}^{\prime}\right)+\log \left(v_{i, 1}\right)$ and, after some algebra we have a more tractable expression of the same model for any $t$ as follows:

$$
\log \left(\mu_{i, t}\right)=\sum_{j=1}^{t-1} R_{j}+\log \left(\mu_{i, 1}^{\prime}\right)+\log \left(v_{i, t}\right)
$$

(1)

\section{Equation (2) expresses any log-transformed expected count in year $t$ as a simple linear} combination of unknown parameters, with the similarly transformed number of visits $v_{i, t}$ (which may vary between sites and years) as a standardising offset (cf. Freeman and Newson, 2008). These parameters, and most usefully the annual growth rates $R_{t}$, are thus readily estimated and compared across surveys by fitting to observed counts for all sites and years via any of the many standard Generalized Linear Model (GLM) software packages. Specifically, 'unknown' counts in years lacking visits can thus be safely ignored.

Butterfly counts are highly variable in their nature and the goodness-of-fit of such models, in which annual trends are constrained to be identical at all sites, is in formal terms rarely good. We therefore adjust standard errors and hypothesis tests rescaling by the Pearson Chi-squared statistic in the standard, 'quasiPoisson' fashion, to compensate for overdispersion.

Maximum likelihood estimates $\hat{R}_{t}$ of the growth rates under the two surveys in a given year $t$ can be compared, using confidence limits based upon their associated estimates of asymptotic standard error, also available from the standard GLM software. We use these to estimate the difference in growth between the two surveys, log-transformed, defined as $d_{t}=R_{\mathrm{t}}(\mathrm{WCBS})-R_{\mathrm{t}}(\mathrm{tBMS})$ along with its 95\% Confidence Limits. Where the confidence limits of the difference between the two surveys $d_{t}$ include zero, we conclude that there is no significant difference between their population change estimates for the year in question. 

the two surveys, since, for either survey:

$$
\hat{N}=\sum_{t=1}^{4} \widehat{R}_{t} ; \quad \operatorname{var}(\hat{N})=\sum_{t=1}^{4} \operatorname{var}\left(\widehat{R}_{t}\right)+2 \sum_{t=1}^{4} \sum_{k=1}^{t-1}\left[\operatorname{cov}\left(\widehat{R}_{t}, \widehat{R}_{k}\right)\right]
$$

and as the annual estimates of growth are independent between surveys confidence limits for the difference in $N$ between the two can be examined and found to include zero or otherwise, giving a test of equality between surveys as above.

\section{Results}

Within lowland England and Wales (Environmental Zones 1 \& 2), traditional BMS transects are predominantly located within areas of relatively high cover of broadleaved woodland and sub-urban land cover, with typically correspondingly lower cover of arable land (Figure 1; Table 1). In contrast, WCBS samples in lowland areas are similar to the average values for the region, as would be expected from a random sample of locations. Within upland regions, $1 \mathrm{~km}$ grid squares sampled by traditional BMS transects and the WCBS are both characterised by relatively low cover of montane habitats. Within upland regions, sampling locations for the WCBS tends to have relatively high cover of arable land and coniferous woodland (Table 1).

Of the butterfly species included in the analysis, there was no overall clear tendency for mean counts (per km of line transect per visit) during the survey period (July and August) to be higher on one survey versus the other, in spite of the minor difference in protocol; 14 out of 26 species had higher counts for WCBS versus traditional BMS transects. Species with notably higher mean counts within WCBS survey squares included the three Pieris species: $P$. brassicae, $P$. napi and $P$. rapae. In contrast, Nymphalidae tended to have higher counts within traditional BMS survey locations, i.e. Maniola jurtina, Aphantopus hyperantus and Erebia aethiops (Table 2). It should be noted, however, that abundance estimates between the two schemes may not be directly comparable. The Wider 
213 Countryside Survey typically samples public rights of way due to the practical difficulties of accessing land within randomly-located $1 \mathrm{~km}$ grid squares; traditional transect routes are likely to be more representative of habitat parcels. Difference in the visibility of butterfly species between habitats can also affect their detectability (Dennis et al. 2006) and ideally is taken into account when comparing population abundance between schemes. Analysis of differences in growth rates between the two schemes, the primary aim of this manuscript, is not affected by these factors. For all but one species (Erebia aethiops, the only predominantly Northern species considered), the number of sites where species were recorded was markedly higher for the traditional BMS survey; mean number of sites per species of 601 for WCBS and 951 for the traditional BMS. The number of samples (visits) was approximately ten times higher for the BMS survey than the WCBS survey with mean number of samples per species of 24,485 and 2306 respectively (Table 2 ). Over the period since the WCBS became fully operational following its full launch in 2009, 12 species had a significantly positive and 5 had a significantly negative change in abundance (Table 2) for this scheme. More species had significant growth rates over this period when sampled by traditional BMS transects, suggesting higher power for this scheme for detecting trends; 15 and 8 species showed a significant positive or negative change respectively over this period. For most species, change was similar between the two schemes, being negative or positive for both surveys over the 2009 to 2013 period. For only 2 species were changes significantly different from zero and in opposite directions for the two schemes. Polyommatus icarus declined within WCBS sites yet increased within traditional BMS transects over this period. In contrast, Pyronia tithonus had traditional BMS transects (Table 2).

There was a significant overall correlation $(\rho=0.75, p<0.001)$ between the population change from the two sampling schemes over the period 2009-2013 (Figure 2). The confidence intervals of the growth rate estimates are larger for the WCBS compared to the traditional BMS (mean Cls: $\mathrm{WCBS}=0.43 ; \mathrm{tBMS}=0.14)$, likely to be caused by fewer sampling visits per year for this scheme. 
When assessing individual year-to-year changes, there was also a significant correlation between the two schemes (Figure 3), and similarly between 2007/2008 and 2008/2009 when the WCBS was being piloted and therefore relatively few locations were sampled. Vanessa cardui is a notable outlier when comparing growth rates between 2008 and 2010 (Figure 3). The significant correlation between population change from the two schemes remains when this species is excluded. $V$. cardui is migratory in the UK, arriving each spring from populations that emerge in North Africa or Southern Europe. Numbers arriving in the UK fluctuate markedly from year to year, depending on conditions in natal areas. Vast numbers arrive in some years, with recent migrant events occurring in 1996 and 2009. Growth in numbers of $V$. cardui during the invasion event of 2009 was higher on traditional BMS sites than Wider Countryside Survey transects. For the period 2009-2013, there was a slight tendency for change to be greater within WCBS than for traditional BMS transects with for $17(65 \%)$ of the 26 species analysed showing this difference (Table 3). Of the 15 species with a significant difference between the two surveys, 12 had a significantly higher growth rate within WCBS survey locations. However, there was no species where the difference in growth rates was in the same direction for all individual year-to-year comparisons (Table 3) showing a lack of consistency in this result. When restricted to significant growth rates, there was some consistency in effects with Polyommatus icarus and Celestrina argiolus having significantly lower growth rates for the WCBS. The three species with a significantly higher growth rates 2009-2013 within traditional BMS transects over 2009-2013 were Pieris rapae, Polyommatus icarus and Erebia aethiops (Table 3).

When assessing year-to-year growth, for most years there is a relatively even split between comparisons (2009/10, 2010/11 and 2011/12), the majority of species had higher growth rates greater on WCBS sites compared to traditional BMS transects. Notably, between 2011 and 2012, growth rate was higher on WCBS transects for 17 out of the 26 species analyses, 11 significantly so. 
In contrast, growth rates were higher on traditional BMS transect sites between 2008 and 2009 for 19 out of 26 species, with this difference statistically significant for 8 species.

\section{Discussion}

There is no strong evidence from this analysis that there is a systematic difference in butterfly population trends between locations sampled by the two UKBMS schemes - the Wider Countryside Butterfly Survey and traditional BMS transects. Comparing species' trends over the main period for comparison (2009-2013), when both schemes were operating fully, there was a strong positive relationship in butterfly population trends between the two schemes. There were only two (out of 26) species where significant trends $2009-2013$ for the two schemes were in opposite directions, i.e. a significant decline for one scheme and a significant increase for the other. However, there were no species for which growth rates differences were consistent for all comparisons over consecutive years; all species performed better on either scheme at some time during the period of analysis. results based solely on analysis of the traditional BMS sites are likely to be validated (for most species) by the Wider Countryside Butterfly Survey. Monitoring data has been a rich resource for assessing the impacts of climate change (e.g. Oliver et al. 2013; Roy and Thomas 2003), habitat management (Woodcock et al. 2012) and conservation policies (Brereton et al. 2008) for example. However, there is considerable scope for using the combined UKBMS surveys to understand further the impact of environmental change on butterfly populations using a more representative sample of the UK. A particular advantage of the combined UKBMS datasets is good coverage of both protected areas and the wider countryside. Although protected areas have been shown to facilitate range expansion (Thomas et al. 2012) and support higher population sizes than non-protected areas (Gillingham et al. 2014), there is a lack of evidence of the influence of site protection on population dynamics (i.e. improved population trends or stability of populations). Similarly, data from the 
combined datasets enables future studies to investigate the effects of habitat composition and configuration (i.e. fragmentation) and land management on butterfly population trends; previous studies addressing these questions have been limited to the traditional UKBMS sites which predominantly sample semi-natural habitats.

Although trends between the two surveys are broadly similar, it should be noted that the traditional BMS enables trends to be reported for a wider set of species, particularly those with smaller ranges and/or tending to occur in rarer habitats which are not sampled sufficiently by the stratified-random set of WCBS locations. The traditional BMS enables trends to be estimated for 56 species for example, compared to the 26 species reported in this paper. The WCBS also has lower power for detecting trends in populations due to fewer visits within the season and therefore greater error in estimates of annual growth rates (Roy et al. 2007). Therefore, a comprehensive UKBMS is ideally composed of both surveys, realising the beneficial features of each. Combined data from the two schemes is also invaluable for assessing the spatial distribution and abundance of butterfly populations (Oliver et al. 2012a), particularly when combined with opportunistic recording data (Pagel et al. 2014). The improved coverage of habitats achieved by combining the WCBS and the traditional BMS transect scheme offers potential for estimation of population abundance on a regional basis. However, although the WCBS improves sampling of previously under-represented habitats such as arable farmland and urban areas, the transect route typically follows public rights of way through sample $1 \mathrm{~km}$ grid squares. Random location of transect routes within a larger $1 \mathrm{~km}$ grid square was shown to not impractical during the design of the scheme (Brereton et al. 2011b). Models to upscale UKBMS data for population estimates therefore need to account for habitat coverage, as well as differences in the detectability of species (Dennis et al. 2006). Butterflies population size and annual fluctuations are known to be strongly affected by climate and weather (Oliver et al. 2012b; Powney et al. 2010; Roy et al. 2001); over the relatively short time periods available for comparison here, weather effects are therefore likely to dominate year-to-year population changes. Given summer temperatures typically show a high degree of 
similarity between locations (i.e. high spatial autocorrelation), we expect UKBMS sites for both schemes (WCBS and traditional BMS) to experience similar conditions within a year. Annual changes in butterfly population size are therefore likely to be broadly similar between the two schemes over short time-periods, as demonstrated here. Such a result is particularly likely for relatively mobile species which can disperse across the UK landscape. Such 'wider countryside' species are those predominantly sampled by the WCBS (Brereton et al. 2011b) and therefore form the basis of the analyses presented here.

Habitat availability and quality are also known to strongly affect butterfly populations (Warren et al. 2001). Habitat associations of butterflies have been shown to vary across geographic ranges (Oliver et al. 2009) with several species restricted to a narrower set of habitats towards the northern used by butterflies in Britain has reduced over the last 40 years, despite predicted expansions in associations through recent climate warming (Oliver et al. 2012c).

Effects of habitat change and associated interactions with climate (Oliver and Morecroft 2014) are typically subtle and have the greatest effects on species which are specialised to localised habitat conditions - species that were not analysed here as they do not occur frequently within WCBS samples. For widespread butterfly species, populations are likely to be sensitive to management of habitats that are common in the landscape, such as farmland. Within the European Union, considerable financial resource is allocated to enhancement of the farmed environment through the Common Agricultural Policy, although the effectiveness of these measures for biodiversity have come into question (Pe'er et al. 2014) unless they are well-designed and implemented effectively (Pywell et al. 2012). Evidence is lacking as to whether such schemes are having a positive effect on butterfly populations. If effective, we would predict butterfly population trends in the wider countryside (where agri-environment schemes are implemented) to be better than within other habitats. Although from this initial assessment we find no evidence of improved trends in the wider countryside versus semi-natural habitats that might be evident if management of the farmed 
environment agri-environment was effective, it is important that monitoring schemes are in place to undertake robust assessments.

Butterfly populations have declined in the UK, markedly since the turn of the 20th Century but also within the more recent period since standardised monitoring began in 1976 (Fox et al. 2006). The decline in the distribution of butterflies has been more marked than for other well monitored taxa, birds and vascular plants (Thomas et al. 2004), stressing the importance of effective monitoring of insects to provide a more representative assessment of the status of biodiversity. The two component sampling schemes of the UKBMS estimate similar population trends for relatively common and widespread species. Together, these schemes provide a strong framework for future assessments of butterfly populations.

\section{Acknowledgements}

The UKBMS is operated by the Centre for Ecology \& Hydrology, Butterfly Conservation and the British Trust for Ornithology and funded by a multi-agency consortium including the Countryside Council for Wales, Defra, the Joint Nature Conservation Committee, Forestry Commission, Natural England, the Natural Environment Research Council, and Scottish Natural Heritage. The UKBMS is indebted to all volunteers who contribute data to the scheme. We thank two anonymous referees for helpful comments on this manuscript.

\section{References}

Brereton T, Roy DB, Middlebrook I, Botham M, Warren M (2011a) The development of butterfly indicators in the United Kingdom and assessments in 2010 Journal of Insect Conservation 15:139-151 doi:10.1007/s10841-010-9333-z

Brereton TM, Cruickshanks KL, Risely K, Noble DG, Roy DB (2011b) Developing and launching a wider countryside butterfly survey across the United Kingdom Journal of Insect Conservation 15:279-290 doi:10.1007/s10841-010-9345-8

Brereton TM, Warren MS, Roy DB, Stewart K (2008) The changing status of the Chalkhill Blue butterfly Polyommatus coridon in the UK: the impacts of conservation policies and environmental factors Journal of Insect Conservation

Carey P et al. (2008) Countryside survey: UK results from 2007 
CBD (2010) Decision X/2, The Strategic Plan for Biodiversity 2011-2020 and the Aichi Biodiversity Targets, Nagoya, Japan, 18 to 29 October 2010. CBD, Nagoya, Japan

Chen I-C, Hill JK, Ohlemueller R, Roy DB, Thomas CD (2011) Rapid Range Shifts of Species Associated with High Levels of Climate Warming Science 333:1024-1026 doi:10.1126/science.1206432

Cowley MJR, Thomas CD, Thomas JA, Warren MS (1999) Flight areas of British butterflies: assessing species status and decline Proceedings of the Royal Society of London B 266:1587-1592

Dempster JP, McLean I (1998) Insect Populations: In Theory and in Practice: 19th Symposium of the Royal Entomological Society, 10-11 September 1997 at the University of Newcastle. Kluwer Academic,

Dennis EB, Freeman SN, Brereton T, Roy DB (2013) Indexing butterfly abundance whilst accounting for missing counts and variability in seasonal pattern Methods in Ecology and Evolution 4:637-645

Dennis RLH, Shreeve TG, Isaac N, Roy DB, Hardy PB, Fox R, Asher J (2006) The effects of visual apparency on bias in butterfly recording and monitoring Biological Conservation 128:486492

Fisher JA, Frank KT, Leggett WC (2010) Dynamic macroecology on ecological time-scales Global Ecology and Biogeography 19:1-15

Fox R, Asher J, Brereton T, Roy D, Warren M (2006) The state of butterflies in Britain and Ireland. Pisces, Newbury

Gillingham PK, Alison J, Roy DB, Fox R, Thomas CD (2014) High abundances of species in protected areas in parts of their geographic distributions colonised during a recent period of climatic change Conservation Letters:n/a-n/a doi:10.1111/conl.12118

Gregory RD, van Strien A, Vorisek P, Meyling AWG, Noble DG, Foppen RPB, Gibbons DW (2005) Developing indicators for European birds Philosophical Transactions- Royal Society of London Series B Biological Sciences:269-288

Hickling R, Roy DB, Hill JK, Fox R, Thomas CD (2006) The distributions of a wide range of taxonomic groups are expanding polewards Global Change Biology 12:450-455

Hochachka WM, Fink D, Hutchinson RA, Sheldon D, Wong W-K, Kelling S (2012) Data-intensive science applied to broad-scale citizen science Trends Ecol Evol 27:130-137

Matechou E, Dennis EB, Freeman SN, Brereton T (2014) Monitoring abundance and phenology in (multivoltine) butterfly species: a novel mixture model Journal of Applied Ecology 51:766775

Miller-Rushing AJ, Primack RB (2008) Global warming and flowering times in Thoreau's Concord: a community perspective Ecology 89:332-341

Morton D et al. (2011) Final Report for LCM2007-the new UK land cover map. Countryside Survey Technical Report No 11/07

Oliver T, Hill JK, Thomas CD, Brereton T, Roy DB (2009) Changes in habitat specificity of species at their climatic range boundaries Ecology Letters 12:1091-1102 doi:10.1111/j.14610248.2009.01367.x

Oliver TH, Brereton T, Roy DB (2013) Population resilience to an extreme drought is influenced by habitat area and fragmentation in the local landscape Ecography 36:579-586 doi:10.1111/j.1600-0587.2012.07665.x

Oliver TH et al. (2012a) Population density but not stability can be predicted from species distribution models Journal of Applied Ecology 49:581-590 doi:10.1111/j.13652664.2012.02138.x

Oliver TH, Morecroft MD (2014) Interactions between climate change and land use change on biodiversity: attribution problems, risks, and opportunities Wiley Interdisciplinary Reviews: Climate Change 5:317-335 doi:10.1002/wcc.271

Oliver TH, Roy DB, Brereton T, Thomas JA (2012b) Reduced variability in range-edge butterfly populations over three decades of climate warming Global Change Biology 18:1531-1539 
Oliver TH, Thomas CD, Hill JK, Brereton T, Roy DB (2012c) Habitat associations of thermophilous butterflies are reduced despite climatic warming Global Change Biology 18:2720-2729 doi:10.1111/j.1365-2486.2012.02737.x

Pagel J et al. (2014) Quantifying range-wide variation in population trends from local abundance surveys and widespread opportunistic occurrence records Methods in Ecology and Evolution 5:751-760 doi:10.1111/2041-210X.12221

Pe'er G et al. (2014) EU agricultural reform fails on biodiversity Science 344:1090-1092 doi:10.1126/science.1253425

Pereira HM et al. (2010) Global biodiversity monitoring Frontiers in Ecology and the Environment 8:459-460

Pereira HM et al. (2013) Essential biodiversity variables Science 339:277-278

Pereira HM, Navarro LM, Martins IS (2012) Global biodiversity change: the bad, the good, and the unknown Annual Review of Environment and Resources 37:25-50 doi:10.1146/annurevenviron-042911-093511

Pollard E (1977) A method of assessing changes in the abundance of butterflies Biological Conservation 12:115-134

Powney G, Roy D, Chapman D, Oliver T (2010) Synchrony of butterfly populations across species' geographic ranges Oikos 119:1690-1696 doi:10.1111/j.1600-0706.2010.18168.x

Pywell RF, Heard MS, Bradbury RB, Hinsley S, Nowakowski M, Walker KJ, Bullock JM (2012) Wildlifefriendly farming benefits rare birds, bees and plants Biology letters 8:772-775

Rothery P, Roy DB (2001) Application of generalized additive models to butterfly transect count data Journal of Applied Statistics 28:897-909

Roy DB, Rothery P, Moss D, Pollard E, Thomas JA (2001) Butterfly numbers and weather: predicting historical trends in abundance and the future effects of climate change Journal of Animal Ecology 70:201-217

Roy DB, Rothery P., Brereton T (2007) Reduced-effort schemes for monitoring butterfly populations Journal of Applied Ecology 44:993-1000

Roy DB, Thomas JA (2003) Seasonal variation in the niche, habitat availability and population fluctuations of a bivoltine thermophilous insect near its range margin. Oecologia 134:439444

Strong DR, Lawton JH, Southwood SR (1984) Insects on plants. Community patterns and mechanisms. Blackwell Scientific Publicatons,

Thomas CD et al. (2012) Protected areas facilitate species' range expansions Proc Natl Acad Sci U S A 109:14063-14068 doi:10.1073/pnas.1210251109

Thomas JA (2005) Monitoring change in the abundance and distribution of insects using butterflies and other indicator groups Philosophical Transactions of the Royal Society B-Biological Sciences 360:339-357

Thomas JA, Clarke RT (2004) Extinction rates and butterflies Science 305:1563-1564

Thomas JA et al. (2004) Comparative losses of British butterflies, birds, and plants and the global extinction crisis Science 303:1879-1881

Warren MS et al. (2001) Rapid responses of British butterflies to opposing forces of climate and habitat change Nature 414:65-69

Woodcock BA, Bullock JM, Mortimer SR, Brereton T, Redhead JW, Thomas JA, Pywell RF (2012) Identifying time lags in the restoration of grassland butterfly communities: a multi-site assessment Biological Conservation 155:50-58 

circles are locations of Wider Countryside Butterfly Survey sites.

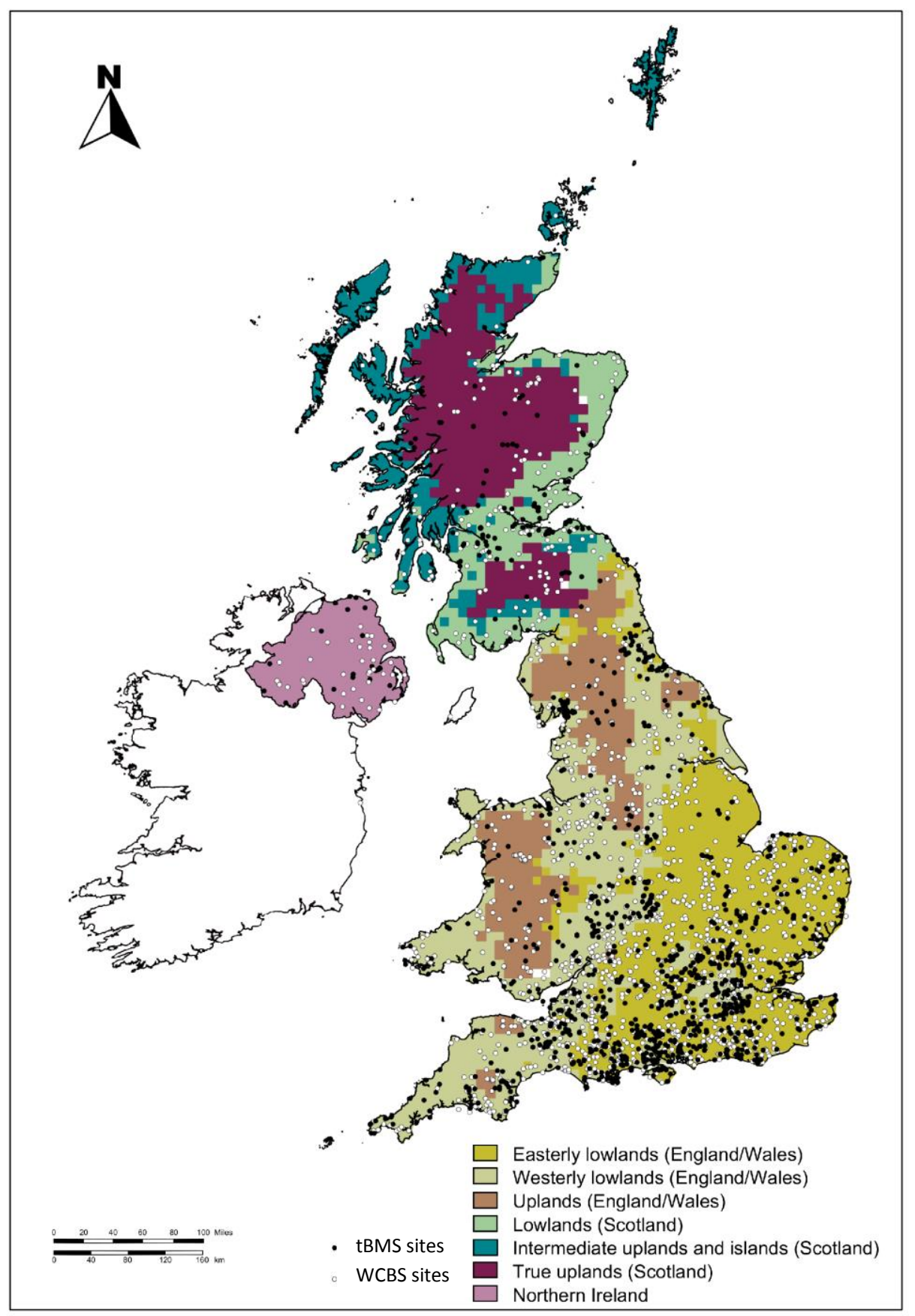


Figure 2. Comparison of log (growth rates) from 2009 to 2013 of the two surveys for 26 species analysed. Solid lines to indicate zero growth for the WCBS (vertical) and tBMS (horizontal) are shown; the dashed line indicates the line of unity where growth rates are equal for the two schemes. Bars represent 1 standard error.

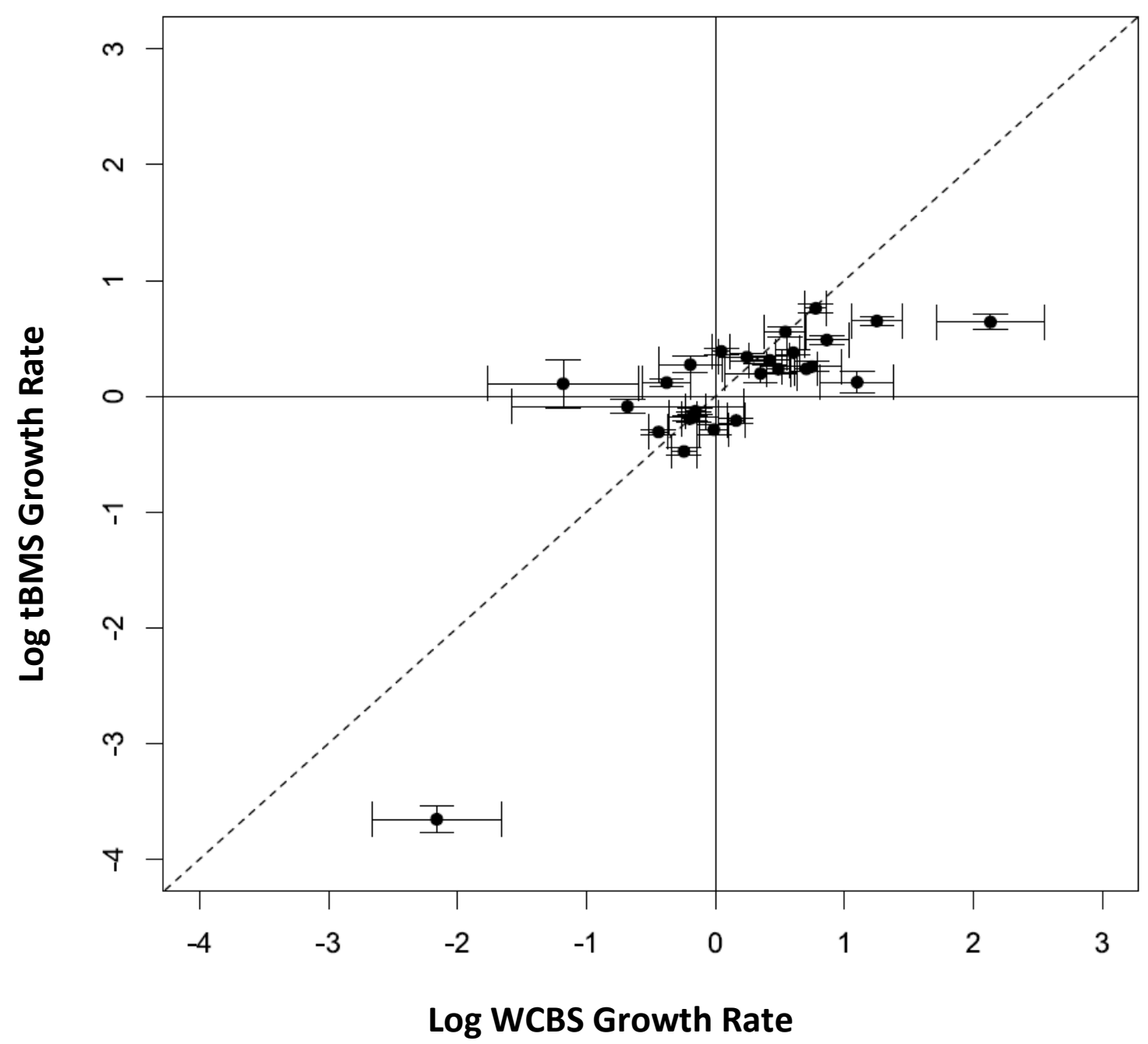


Figure 3. Comparison of year-to-year growth rates from 2007 and 2013 of the two surveys for 26 species analysed. ; the dashed line indicates the line of unity where growth rates are equal for the two schemes. Bars represent 1 standard error.
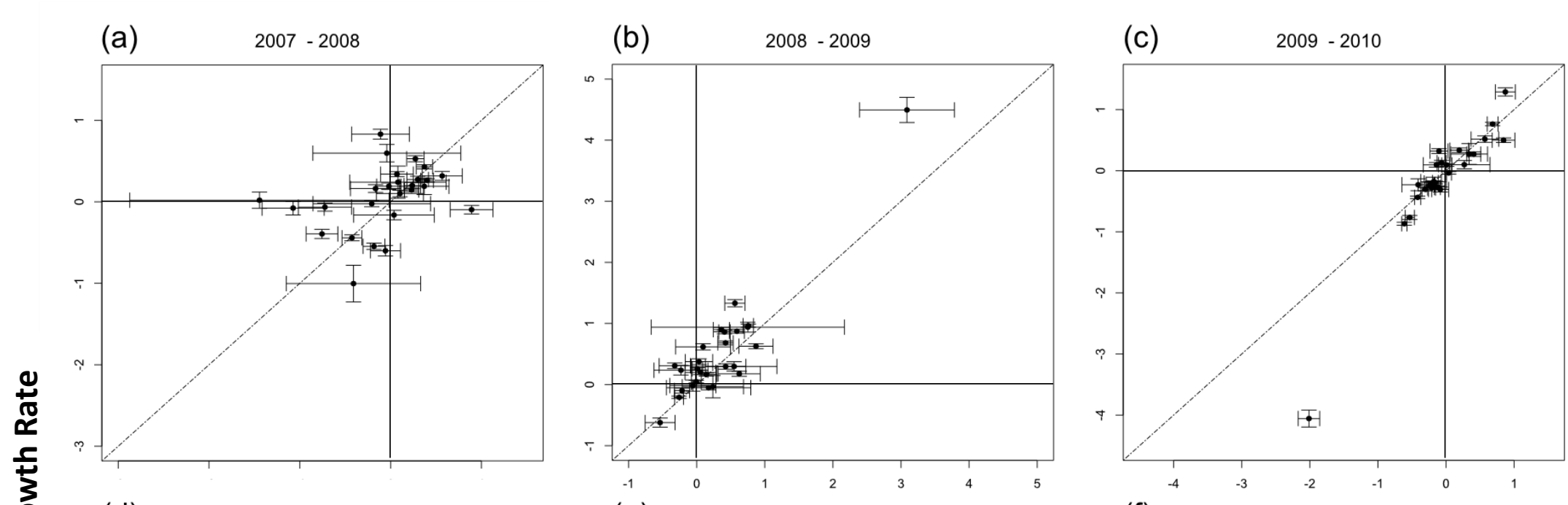

(e)
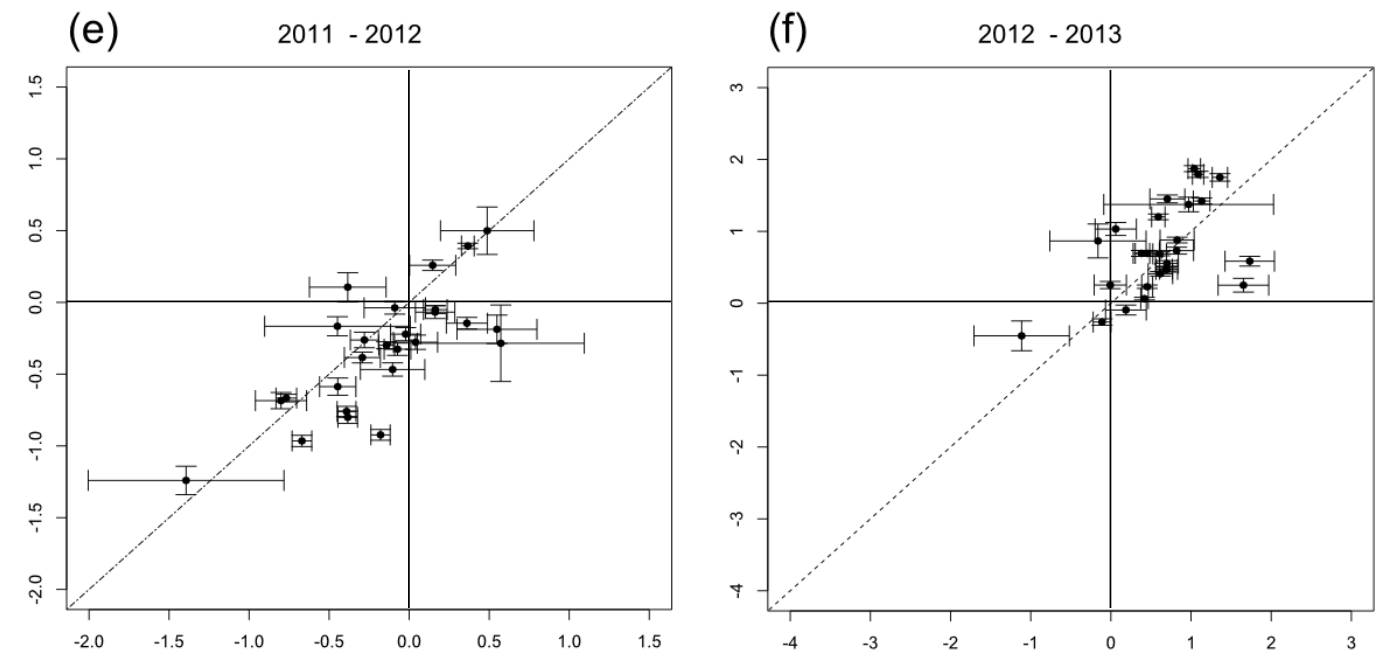

Log WCBS Growth Rate 


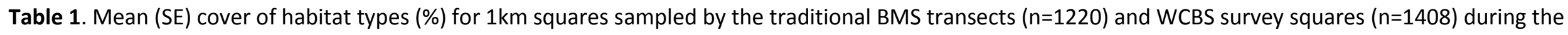

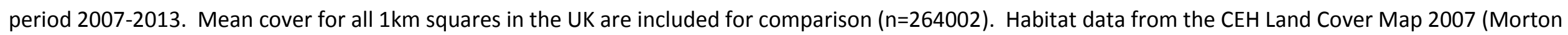
et al. 2011).

(table overleaf to fit on a single page)

${ }^{a}$ Fen, Marsh and Swamp \& Bogs

b Salt water and freshwater

${ }^{c}$ Littoral and supra-littoral rocks and sediments (sand dunes, saltmarsh) 


\begin{tabular}{|c|c|c|c|c|c|c|c|c|c|c|c|c|}
\hline $\begin{array}{l}\text { Zone } \\
\text { Scheme }\end{array}$ & $\begin{array}{l}\text { Broadleaved } \\
\text { woodland }\end{array}$ & $\begin{array}{l}\text { Coniferous } \\
\text { woodland }\end{array}$ & $\begin{array}{l}\text { Arable and } \\
\text { horticulture }\end{array}$ & $\begin{array}{l}\text { Improved } \\
\text { grassland }\end{array}$ & $\begin{array}{l}\text { Natural } \\
\text { grassland }\end{array}$ & Wetland $^{\text {b }}$ & Heath & $\begin{array}{l}\text { Montane } \\
\text { habitats }\end{array}$ & Inland rock & Water $^{c}$ & $\begin{array}{l}\text { Coastal } \\
\text { habitats }^{\mathrm{d}}\end{array}$ & $\begin{array}{l}\text { Urban } \\
\text { Suburban } \\
\end{array}$ \\
\hline \multicolumn{13}{|c|}{ Zone 1. Easterly lowlands (England/Wales) } \\
\hline tBMS & $20.16(0.86)$ & $3.30(0.41)$ & $28.82(1.06)$ & $26.21(0.87)$ & $7.00(0.40)$ & $0.78(0.30)$ & $2.01(0.37)$ & $0.00(0.00)$ & $0.43(0.09)$ & $1.33(0.25)$ & $0.31(0.14)$ & $9.52(0.70)$ \\
\hline WCBS & $10.02(0.56)$ & $2.93(0.45)$ & $48.95(1.20)$ & $26.35(0.82)$ & $4.23(0.29)$ & $0.03(0.01)$ & $0.54(0.16)$ & $0.00(0.00)$ & $0.37(0.09)$ & $0.58(0.12)$ & $0.18(0.10)$ & $5.92(0.54)$ \\
\hline all zone & 7.87 & 1.68 & 53.37 & 24.06 & 4.90 & 0.13 & 0.56 & 0.00 & 0.26 & 0.75 & 0.37 & 5.94 \\
\hline \multicolumn{13}{|c|}{ Zone 2. Westerly lowlands (England/Wales) } \\
\hline tBMS & $18.27(0.88)$ & $3.48(0.43)$ & $21.34(0.96)$ & $28.50(0.96)$ & $7.08(0.47)$ & $0.98(0.32)$ & $1.52(0.27)$ & $0.00(0.00)$ & $0.62(0.14)$ & $1.78(0.26)$ & $4.62(0.67)$ & $9.22(0.76)$ \\
\hline WCBS & $9.01(0.63)$ & $2.35(0.32)$ & $33.44(1.27)$ & $34.82(1.10)$ & $7.55(0.43)$ & $0.19(0.16)$ & $0.74(0.20)$ & $0.00(0.00)$ & $0.35(0.11)$ & $1.20(0.24)$ & $1.52(0.36)$ & $7.97(0.84)$ \\
\hline all zone & 7.24 & 2.09 & 33.2 & 35.33 & 7.18 & 0.17 & 0.90 & 0.00 & 0.33 & 1.36 & 2.43 & 7.56 \\
\hline \multicolumn{13}{|c|}{ Zone 3. Uplands (England/Wales) } \\
\hline BMS & $9.88(1.53)$ & $7.37(2.33)$ & $8.43(2.06)$ & $31.22(3.91)$ & $24.24(2.78)$ & $3.45(2.31)$ & $8.96(1.77)$ & $0.00(0.00)$ & $2.39(1.58)$ & $1.29(0.71)$ & $0.00(0.00)$ & $3.06(1.38)$ \\
\hline WCBS & $4.86(0.70)$ & $8.80(1.61)$ & $3.91(0.73)$ & $31.53(2.65)$ & $28.16(2.24)$ & $9.19(2.23)$ & $10.52(1.68)$ & $0.00(0.00)$ & $0.15(0.06)$ & $0.93(0.42)$ & $0.00(0.00)$ & $2.02(0.63)$ \\
\hline all zone & 4.27 & 8.27 & 4.17 & 27.56 & 28.30 & 8.77 & 14.82 & 1.48 & 0.58 & 0.67 & 0.00 & 1.30 \\
\hline \multicolumn{13}{|c|}{ Zone 4. Lowlands (Scotland) } \\
\hline BMS & $13.42(1.54)$ & $13.29(2.31)$ & $11.28(2.06)$ & $21.25(2.38)$ & $9.88(1.43)$ & $1.07(0.74)$ & $3.08(0.87)$ & $0.00(0.00)$ & $0.76(0.35)$ & $5.97(1.69)$ & $5.60(2.05)$ & $13.07(2.41)$ \\
\hline WCBS & $7.10(0.97)$ & $8.23(1.68)$ & $30.58(3.28)$ & $31.27(2.46)$ & $9.77(1.19)$ & $3.63(1.59)$ & $2.29(0.53)$ & $0.00(0.00)$ & $0.33(0.12)$ & $1.18(0.46)$ & $0.20(0.11)$ & $4.73(1.49)$ \\
\hline all zone & 5.82 & 10.85 & 26.13 & 30.04 & 10.79 & 2.72 & 4.56 & 0.00 & 0.48 & 1.96 & 1.16 & 3.90 \\
\hline \multicolumn{13}{|c|}{ Zone 5. Intermediate uplands and islands (Scotland) } \\
\hline BMS & $9.68(3.02)$ & $13.88(4.34)$ & $2.36(0.97)$ & $16.68(3.96)$ & $16.12(4.41)$ & $1.12(1.00)$ & $9.60(2.95)$ & $0.00(0.00)$ & $0.48(0.25)$ & $7.28(3.26)$ & $6.64(2.42)$ & $4.16(1.79)$ \\
\hline WCBS & $4.38(1.30)$ & $20.83(4.79)$ & $5.29(1.79)$ & $14.69(2.93)$ & $17.85(2.75)$ & $6.75(2.81)$ & $22.00(4.22)$ & $0.00(0.00)$ & $0.44(0.20)$ & $1.73(0.76)$ & $2.23(1.70)$ & $1.48(0.89)$ \\
\hline all zone & 2.62 & 11.22 & 2.91 & 10.67 & 17.20 & 14.24 & 18.91 & 0.15 & 0.91 & 3.52 & 2.67 & 0.59 \\
\hline \multicolumn{13}{|c|}{ Zone 6. True Uplands (Scotland) } \\
\hline BMS & $1.32(0.45)$ & $17.89(6.73)$ & $1.11(0.67)$ & $4.11(1.93)$ & $34.05(6.77)$ & $5.32(3.15)$ & $25.74(5.78)$ & 6.47 (4.99) & $0.26(0.21)$ & $3.68(2.35)$ & $0.00(0.00)$ & $0.16(0.12)$ \\
\hline WCBS & $2.29(0.70)$ & $32.92(4.92)$ & $2.94(1.65)$ & $4.54(1.60)$ & $21.02(3.85)$ & $3.63(1.14)$ & 27.67 (4.54) & $2.29(2.09)$ & $0.54(0.28)$ & $2.15(1.36)$ & $0.00(0.00)$ & $0.21(0.11)$ \\
\hline all zone & 1.69 & 13.04 & 0.84 & 3.66 & 26.51 & 9.04 & 28.29 & 14.00 & 1.03 & 1.91 & 0.01 & 0.09 \\
\hline \multicolumn{13}{|c|}{ Zone 7. Northern Ireland } \\
\hline BMS & $8.81(1.83)$ & $9.28(2.77)$ & $3.47(1.00)$ & $24.76(4.79)$ & $14.77(3.53)$ & $3.74(2.94)$ & $5.79(1.92)$ & $0.00(0.00)$ & $0.16(0.11)$ & $7.16(3.03)$ & 7.98 (3.97) & $8.92(3.05)$ \\
\hline WCBS & $3.01(0.90)$ & $2.42(0.99)$ & $6.49(1.02)$ & $58.18(4.26)$ & $13.50(2.03)$ & $1.83(1.46)$ & $5.59(2.78)$ & $0.00(0.00)$ & $0.90(0.26)$ & $1.96(1.41)$ & $0.12(0.12)$ & $5.96(2.00)$ \\
\hline all zone & 1.79 & 2.16 & 2.87 & 23.47 & 6.52 & 3.06 & 2.42 & 0.02 & 0.32 & 2.50 & 0.30 & 2.13 \\
\hline \multicolumn{13}{|c|}{ UK (all zones) } \\
\hline BMS & $17.84(0.55)$ & $4.73(0.35)$ & $22.51(0.67)$ & $26.41(0.61)$ & $8.71(0.36)$ & $1.13(0.23)$ & $2.79(0.27)$ & $0.10(0.08)$ & $0.60(0.10)$ & $2.07(0.21)$ & $2.56(0.31)$ & $9.08(0.47)$ \\
\hline WCBS & $8.45(0.34)$ & $5.25(0.41)$ & $35.09(0.83)$ & $29.27(0.63)$ & $8.92(0.38)$ & $1.49(0.26)$ & $3.40(0.34)$ & $0.08(0.07)$ & $0.36(0.05)$ & $0.96(0.12)$ & $0.63(0.13)$ & $5.76(0.38)$ \\
\hline all UK & 5.17 & 5.71 & 23.84 & 23.43 & 12.41 & 4.20 & 8.01 & 1.86 & 0.50 & 1.64 & 1.07 & 3.93 \\
\hline
\end{tabular}


Table 2. Sample size, mean count and estimated population change 2009-2013 for the two schemes. The number of sites for the two schemes are: WCBS - 1366 sites; tBMS - 1446 sites. Mean counts are standardised to number of individuals per $1 \mathrm{~km}$ linear transect during July and August. A log (growth rate) of zero is a stable population, i.e. no change.

\begin{tabular}{|c|c|c|c|c|c|c|c|}
\hline \multirow[t]{2}{*}{ Species } & \multirow[t]{2}{*}{ Common name } & \multicolumn{3}{|l|}{ WCBS } & \multicolumn{3}{|l|}{ BMS } \\
\hline & & Sites (visits) & Mean Count (se) & Log (growth rate) & Sites (visits) & Mean Count (se) & Log (growth rate) \\
\hline Thymelicus sylvestris & Small Skipper & 415 (1490) & $2.05(0.32)$ & $0.42^{* *}$ & 891 (20717) & $1.87(0.04)$ & $0.31^{* * *}$ \\
\hline Thymelicus lineola & Essex Skipper & $168(550)$ & $1.06(0.10)$ & $1.10 * * *$ & 376 (6893) & $0.71(0.06)$ & 0.12 \\
\hline Ochlodes sylvanus & Large Skipper & 390 (1404) & $0.88(0.04)$ & $0.86 * * *$ & 1056 (28583) & $0.77(0.02)$ & $0.49^{* * *}$ \\
\hline Gonepteryx rhamni & Brimstone & $319(982)$ & $0.55(0.04)$ & 0.24 & $952(26728)$ & $0.58(0.01)$ & $0.34^{* * *}$ \\
\hline Pieris brassicae & Large White & $1140(5020)$ & $3.91(0.10)$ & $-0.20 * * *$ & 1305 (36332) & $2.21(0.04)$ & $-0.19 * * *$ \\
\hline Pieris napi & Green-veined White & $1061(4373)$ & $3.63(0.10)$ & -0.15 & 1281 (34479) & $2.28(0.03)$ & $-0.13 * * *$ \\
\hline Pieris rapae & Small White & $1134(4995)$ & $5.18(0.13)$ & 0.05 & 1292 (36107) & $2.62(0.05)$ & $0.39 * * *$ \\
\hline Lycaena phlaeas & Small Copper & 482 (1449) & $0.70(0.03)$ & -0.16 & 1105 (26436) & $0.59(0.01)$ & $-0.18 * * *$ \\
\hline Aricia agestis & Brown Argus & $174(504)$ & $1.00(0.10)$ & -0.68 & $576(13304)$ & $0.94(0.03)$ & -0.09 \\
\hline Polyommatus icarus & Common Blue & $643(2192)$ & $1.78(0.08)$ & $-0.38^{*}$ & 1192 (31653) & $3.16(0.06)$ & $0.12 * * *$ \\
\hline Celastrina argiolus & Holly Blue & $442(1412)$ & $0.60(0.03)$ & 0.35 & $982(22790)$ & $0.25(0.01)$ & $0.20 *$ \\
\hline Aglais urticae & Small Tortoiseshell & $931(3423)$ & $1.60(0.06)$ & $0.78 * * *$ & $1221(29640)$ & $0.58(0.02)$ & $0.76^{* * *}$ \\
\hline Aglais io & Peacock & $968(3587)$ & $1.33(0.05)$ & $0.49 * * *$ & 1306 (36509) & $1.35(0.04)$ & $0.23^{* * *}$ \\
\hline Polygonia c-album & Comma & $700(2631)$ & $0.66(0.02)$ & $-0.24^{*}$ & $1114(30120)$ & $0.49(0.01)$ & $-0.48 * * *$ \\
\hline Argynnis aglaja & Dark Green Fritillary & $74(185)$ & $0.84(0.11)$ & $2.13^{* * *}$ & $383(8205)$ & $1.52(0.06)$ & $0.64^{* * *}$ \\
\hline Argynnis paphia & Silver-washed & $126(479)$ & $1.26(0.13)$ & $0.75^{* *}$ & 485 (11344) & $1.98(0.05)$ & $0.26^{* * *}$ \\
\hline Pararge aegeria & Speckled Wood & 955 (4079) & $1.99(0.05)$ & $-0.44 * * *$ & 1196 (34147) & $2.32(0.03)$ & $-0.31 * * *$ \\
\hline Lasiommata megera & Wall Brown & $174(530)$ & $1.21(0.13)$ & -0.19 & 418 (7978) & $0.51(0.02)$ & $0.27^{* * *}$ \\
\hline Melanargia galathea & Marbled White & $222(743)$ & $2.07(0.20)$ & $1.25^{* * *}$ & $657(18392)$ & $4.81(0.11)$ & $0.65^{* * *}$ \\
\hline Pyronia tithonus & Gatekeeper & $991(4656)$ & $5.17(0.13)$ & $0.16^{*}$ & 1092 (32166) & $8.02(0.09)$ & $-0.21 * * *$ \\
\hline Maniola jurtina & Meadow Brown & $1213(5462)$ & $7.55(0.17)$ & $0.60 * * *$ & 1332 (37969) & $17.42(0.17)$ & $0.38 * * *$ \\
\hline Aphantopus hyperantus & Ringlet & $853(3413)$ & $5.06(0.20)$ & $0.71 * * *$ & 1164 (31277) & $8.05(0.14)$ & $0.24^{* * *}$ \\
\hline Coenonympha & Small Heath & 363 (1116) & $1.60(0.10)$ & $0.54^{* * *}$ & 914 (21016) & $1.92(0.04)$ & $0.56^{* * *}$ \\
\hline Erebia aethiops & Scotch Argus & 63 (182) & $10.88(1.54)$ & -1.18 & $28(674)$ & $16.56(1.39)$ & 0.11 \\
\hline Vanessa atalanta & Red Admiral & 944 (3490) & $0.88(0.02)$ & -0.01 & $1288(34259)$ & $0.57(0.01)$ & $-0.29 * * *$ \\
\hline Vanessa cardui & Painted Lady & 675 (1607) & $2.76(0.24)$ & $-2.16 * * *$ & 1121 (18887) & $1.70(0.09)$ & $-3.66 * * *$ \\
\hline
\end{tabular}


Table 3. Differences in (log) annual growth rates per year, $R_{t}(W C B S)-R_{t}(t B M S)$, and in (log) total growth 2009-2013 with $95 \%$ Confidence Limits. Species with asterisks indicate a statistically significant difference $(p<0.05)$.

\begin{tabular}{|c|c|c|c|c|c|c|c|}
\hline Species & $2007 / 08$ & $2008 / 09$ & $2009 / 10$ & $2010 / 11$ & $2011 / 12$ & $2012 / 13$ & 2009-2013 \\
\hline Thymelicus sylvestris & $-0.33(-0.89,0.23)$ & $0.44(-0.17,1.05)$ & $0.22(-0.03,0.47)$ & $-0.04(-0.29,0.21)$ & $0.15(-0.10,0.40)$ & $-0.24(-0.54,0.06)$ & $0.11(-0.22,0.40)$ \\
\hline Thymelicus lineola & $0.18(-0.38,0.74)$ & $-0.04(-0.73,0.65)$ & $-0.12(-0.67,0.43)$ & $0.18(-0.37,0.73)$ & $-0.47(-1.02,0.08)$ & $1.40(0.74,2.06)^{*}$ & $0.98(0.40,1.58)^{*}$ \\
\hline Ochlodes sylvanus & $-0.65(-1.23,-0.07)^{*}$ & $0.12(-0.47,0.71)$ & $-0.23(-0.52,0.06)$ & $-0.10(-0.37,0.17)$ & $0.56(0.29,0.83)^{*}$ & $0.15(-0.14,0.44)$ & $0.38(0.02,0.74)^{*}$ \\
\hline Gonepteryx rhamni & $0.00(-0.52,0.52)$ & $-0.15(-0.61,0.31)$ & $-0.01(-0.26,0.24)$ & $0.07(-0.25,0.39)$ & $-0.09(-0.48,0.30)$ & $-0.05(-0.47,0.37)$ & $-0.09(-0.51,0.35)$ \\
\hline Pieris brassicae & $-0.26(-0.47,-0.05)^{*}$ & $-0.20(-0.37,-0.03)^{*}$ & $0.24(0.14,0.34)^{*}$ & $0.03(-0.08,0.14)$ & $0.42(0.27,0.57)^{*}$ & $-0.70(-0.86,-0.54)^{*}$ & $0.00(-0.13,0.11)$ \\
\hline Pieris napi & $0.03(-0.22,0.28)$ & $-0.28(-0.50,-0.06)^{*}$ & $0.00(-0.11,0.11)$ & $-0.18(-0.29,-0.07)^{*}$ & $0.76(0.62,0.90)^{*}$ & $-0.61(-0.79,-0.43)^{*}$ & $-0.03(-0.19,0.13)$ \\
\hline Pieris rapae & $0.04(-0.15,0.23)$ & $-0.45(-0.62,-0.28)^{*}$ & $0.17(0.07,0.27)^{*}$ & $0.06(-0.05,0.17)$ & $0.26(0.11,0.41)^{*}$ & $-0.83(-1.01,-0.65)^{*}$ & $-0.34(-0.48,-0.20)^{*}$ \\
\hline Lycaena phlaeas & $0.20(-0.67,1.07)$ & $-0.53(-1.32,0.26)$ & $0.15(-0.08,0.38)$ & $-0.17(-0.4,0.06)$ & $0.30(0.01,0.59)^{*}$ & $-0.26(-0.66,0.14)$ & $0.02(-0.36,0.40)$ \\
\hline Aricia agestis & $-1.46(-4.27,1.35)$ & $-0.19(-2.98,2.60)$ & $0.05(-0.35,0.45)$ & $-0.11(-0.5,0.28)$ & $-0.13(-1.34,1.08)$ & $-0.40(-2.49,1.69)$ & $-0.59(-2.36,1.18)$ \\
\hline Polyommatus icarus & $-0.94(-1.58,-0.3)^{*}$ & $0.24(-0.26,0.74)$ & $-0.09(-0.26,0.08)$ & $0.46(0.27,0.65)$ & $-0.11(-0.44,0.22)$ & $-0.75(-1.19,-0.31)^{*}$ & $-0.50(-0.86,-0.12)^{*}$ \\
\hline Celastrina argiolus & $-0.37(-0.72,-0.02)^{*}$ & $0.08(-0.37,0.53)$ & $-0.40(-0.72,-0.08)^{*}$ & $0.18(-0.02,0.38)$ & $0.08(-0.18,0.34)$ & $0.28(-0.23,0.79)$ & $0.15(-0.43,0.71)$ \\
\hline Aglais urticae & $0.54(0.19,0.89)^{*}$ & $-0.77(-1.09,-0.45)^{*}$ & $0.02(-0.14,0.18)$ & $0.35(0.18,0.52)^{*}$ & $0.05(-0.16,0.26)$ & $-0.39(-0.61,-0.17)^{*}$ & $0.02(-0.16,0.22)$ \\
\hline Aglais io & $0.37(0.12,0.62)^{*}$ & $-0.54(-0.79,-0.29)^{*}$ & $0.29(0.13,0.45)^{*}$ & $0.06(-0.14,0.26)$ & $0.20(0.00,0.40)$ & $-0.29(-0.5,-0.08)^{*}$ & $0.25(0.06,0.46)^{*}$ \\
\hline Polygonia c-album & $-0.21(-0.48,0.06)$ & $-0.26(-0.48,-0.04)^{*}$ & $0.06(-0.07,0.19)$ & $0.21(0.05,0.37)^{*}$ & $0.26(0.08,0.44)^{*}$ & $-0.31(-0.52,-0.1)^{*}$ & $0.23(0.03,0.41)^{*}$ \\
\hline Argynnis aglaja & $-0.99(-1.67,-0.31)^{*}$ & $-0.46(-1.26,0.34)$ & $0.38(-0.47,1.23)$ & $0.19(-0.86,1.24)$ & $-0.22(-1.15,0.71)$ & $1.15(0.53,1.77)^{*}$ & $1.49(0.67,2.33)^{*}$ \\
\hline Argynnis paphia & $0.99(0.50,1.47)^{*}$ & $-0.34(-0.74,0.06)$ & $0.2(-0.14,0.54)$ & $-0.24(-0.56,0.08)$ & $0.45(0.06,0.84)^{*}$ & $0.09(-0.33,0.51)$ & $0.49(0.05,0.95)^{*}$ \\
\hline Pararge aegeria & $-0.06(-0.24,0.12)$ & $-0.25(-0.41,-0.09)^{*}$ & $0.01(-0.08,0.10)$ & $0.02(-0.09,0.13)$ & $-0.09(-0.22,0.04)$ & $-0.08(-0.25,0.09)$ & $-0.13(-0.29,0.01)$ \\
\hline Lasiommata megera & $-0.64(-2.24,0.96)$ & $0.25(-0.99,1.49)$ & $0.00(-0.40,0.40)$ & $-0.38(-0.86,0.1)$ & $0.89(0.36,1.42)^{*}$ & $-0.97(-1.51,-0.43)$ & $-0.47(-0.97,0.05)$ \\
\hline Melanargia galathea & $-0.19(-1.47,1.09)$ & $0.22(-1.00,1.44)$ & $-0.29(-0.67,0.09)$ & $0.80(0.44,1.16)^{*}$ & $-0.12(-0.41,0.17)$ & $0.21(-0.09,0.51)$ & $0.60(0.21,0.99)^{*}$ \\
\hline Pyronia tithonus & $0.08(-0.08,0.24)$ & $-0.06(-0.20,0.08)$ & $0.07(-0.02,0.16)$ & $-0.09(-0.20,0.02)$ & $0.17(0.06,0.28)^{*}$ & $0.22(0.08,0.36)^{*}$ & $0.37(0.23,0.51)^{*}$ \\
\hline Maniola jurtina & $0.14(0.00,0.28)$ & $-0.05(-0.19,0.09)$ & $0.02(-0.07 .0 .11)$ & $-0.15(-0.24,-0.06)^{*}$ & $-0.00(-0.09,0.09)$ & $0.36(0.25,0.47)^{*}$ & $0.23(0.13,0.33)^{*}$ \\
\hline Aphantopus hyperantus & $-0.27(-0.63,0.09)$ & $-0.03(-0.35,0.29)$ & $-0.09(-0.25,0.07)$ & $0.16(-0.01,0.33)$ & $0.18(0.03,0.33) *$ & $0.22(0.05,0.39)^{*}$ & $0.47(0.28,0.66)^{*}$ \\
\hline Coenonympha pamphilus & $0.25(-0.20,0.70)$ & $-0.63(-1.09,-0.17)^{*}$ & $-0.43(-0.72,-0.14)^{*}$ & $0.03(-0.24,0.30)$ & $0.16(-0.09,0.41)$ & $0.23(-0.04,0.50)$ & $-0.01(-0.31,0.29)$ \\
\hline Erebia aethiops & $-0.16(-1.27,0.95)$ & $0.27(-0.68,1.22)$ & $0.10(-0.55 .0 .75)$ & $-0.65(-1.41,0.11)$ & $-0.07(-0.75,0.61)$ & $-0.66(-1.89,0.57)$ & $-1.29(-2.50,-0.06)^{*}$ \\
\hline Vanessa atalanta & $0.01(-0.22,0.24)$ & $-0.12(-0.35,0.11)$ & $-0.17(-0.33,-0.01)^{*}$ & $-0.09(-0.22,0.04)$ & $0.38(0.24,0.52)^{*}$ & $0.15(-0.08,0.38)$ & $0.28(0.02,0.52)^{*}$ \\
\hline Vanessa cardui & $0.59(-0.92,2.10)$ & $-1.4(-2.83,0.03)$ & $2.05(1.63,2.47)^{*}$ & $-0.36(-1.20,0.48)$ & $0.83(-0.29,1.95)$ & $-1.03(-2.3,0.24)$ & $1.49(0.49,2.49)^{*}$ \\
\hline $\begin{array}{l}\text { N. species with WCBS } \\
\text { growth higher (N sign.) }\end{array}$ & $13(3)$ & $6(0)$ & $17(4)$ & $14(3)$ & $17(11)$ & $11(5)$ & $17(12)$ \\
\hline $\begin{array}{l}\text { N. species with tBMS } \\
\text { growth higher (N sign.) }\end{array}$ & $13(5)$ & $19(8)$ & $9(3)$ & $12(2)$ & $9(0)$ & $15(7)$ & $9(3)$ \\
\hline
\end{tabular}

